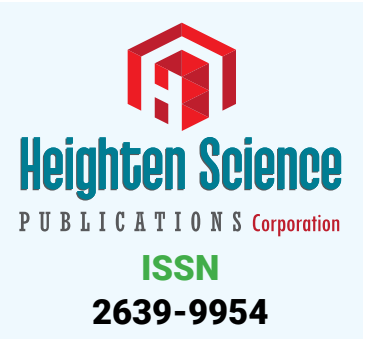

*Address for Correspondence: Henrik Permin, Consultat, M.D., D.Sci., Department of Respiratory Diseases, Bispebjerg Hospital, Dk-2400, Copenhagen, Denmark, Email:

henrik.permin@regionh.dk

Submitted: 02 January 2019

Approved: 17 January 2019

Published: 18 January 2019

Copyright: @ 2019 Permin H, et al. This is an open access article distributed under the Creative Commons Attribution License, which permits unrestricted use, distribution, and reproduction in any medium, provided the original work is properly cited

Check for updates
Review Article

\section{Stethoscope - Over 200 years}

\author{
Henrik Permin* and Svend Norn \\ Department of Respiratory Diseases, Bispebjerg Hospital, Dk-2400, Copenhagen, Denmark
}

With the invention of the stethoscope, in the early 1800s, a better diagnosis of heart and lung disorders was opened up. Through the stethoscope's 200-year history, there has been a significant development of the stethoscopy from the use of the simple monaural earpiece to the binaural stethoscope, followed by the electronic stethoscope, which, together with other studies, has enabled a thorough diagnosis of these disorders. Here is a glimpse of this story.

\section{The cross-border investigation}

Far back in time, it has been clear that the function of the heart and lungs played an important role in maintaining life. By tapping with the finger (percussion) and putting the ear to the patient's chest (auscultation), it could hear sound from the body telling about the patient's condition, especially about the presence of fluid or air-filled organs. Auscultation is already described in the Corpus Hippocraticum, in the Diseases II section [1]. The doctor puts the ear to the chest of a patient with water sores, to hear the pain as a wine vinegar from the lungs - or the doctor grabs the patient about the shoulders, shakes him and places his ear to his chest to hear in which side his pleuritis is sitting. Since then, auscultation seems to have been partially forgotten, although it has probably been known by Ambroise Paré and William Harvey [2]. It was not until the late 1700s that it became an important diagnostic aid, just like the pulse clock and the medical thermometer [3 p. 277]. Here, Joseph Leopold Auenbrugger (1722-1809) is considered to be the father of the modern physical examination, which is based on percussion. Percussion he performed by knocking direcly on the thorax with the finger or cupped hands. His discovery of the percussion sounds from the chest during inhaling and exhaling originates from his work in 1760 at the Vienna Military Hospital [4]. In 1761, His little book on thoracic percussion revealing thoracic diseases appeared in 1761 [3p.271], which in 1808 was translated into French by the Parisian physician Jean Nicolas Corvisart des Marets (1755-1821). This contributed to the French doctors starting to use percussion and ausculation more routinely [5].

The limitation of simple auscultation was the fact that the sound was weak and incomplete and therefore there was a need for improved sound quality. In addition, the direct contact with the patient's body could seem insulting.

\section{Laënnecs monaural stethoscope}

Improvement was obtained in 1816, when the stethoscope was invented by the French physician Rene Theophile Hyacinthe Laënnec (1781-1826) (Figure 1). Laënnec was a military surgeon during the Revolution and Napoleon era. Then he followed with great enthusiasm and research the medical study in Paris and later became the chief physician at Hôpital Necker in Paris as well as professor at the medical faculty [5]. In 1819 he summarized his studies with the stethoscope in a two-volume work on more than 900 pages [3 p. 330]. Laënnec was then attacked by tuberculosis and had to spend two years in Brittany, where he studied the Celtic language. He then resumed his work, and in 1826 a new edition of his book was published, characterized by the experiences 
he had later harvested. Laënnec's great interest in the tuberculosis in connection with his patients and the section hut became his fate, which after several years of illness led to his early death, 45 years old.

Laënnec's invention of the stethoscope originated from the difficulty of examining a fat young woman with heart problems. Therefore, during the examination, he rolled a piece of paper into a tube and placed one end of the tube on the girl's chest and the other end against his ear. The inspiration for this is said to be some children's play with wooden pieces that reinforced the sound of a scraper at the other end of the tree. To his delight, Laënnec discovered that the body sounds became clearer. This caused him to develop a tube in wood - the first monaural stethoscope [6] (Figure 2). For medical reasons, the tube was later modified so that it could be separated into two parts, and it was fitted with a removable funnel at one end. Laënnec stated that the complete device is best to hear heart sounds while the respiratory sounds are heard most clearly when the small funnel is removed [5].

As mentioned, Laënnec published his clinical observations of cardiovascular and lung disorders using the stethoscope in a two-volume work in 1819 [7]. The second edition appeared in 1826 shortly before his death. Here also the description of the fetal heart sounds, i.e. the auscultatory signs of a living fetus - a work carried out by his friend Jacques A. le Jumeau de Kergaradec (1787-1877) [8]. These works describe the clinical aspects and pathology of the diseases, as well as the relationship between the stethoscopic sounds and the clinic and post-mortem findings [4]. Laënnec was first and foremost a pathologist and diagnostician. He was a skilled teacher, which helped many doctors go to Paris to learn the new diagnostic method. Nevertheless, it must be acknowledged that his stethoscopy was initially ignored and ridiculed by

Figure 1: Clean Theophile Hyacinthe Laënnec (1781-1826) examines a patient with pulmonary tuberculosis with his
monaural stethoscope in hand at the Necker Hospital in Paris in 1816 . Gouache after Thaobald Chartran (Wellcome
Library, London).

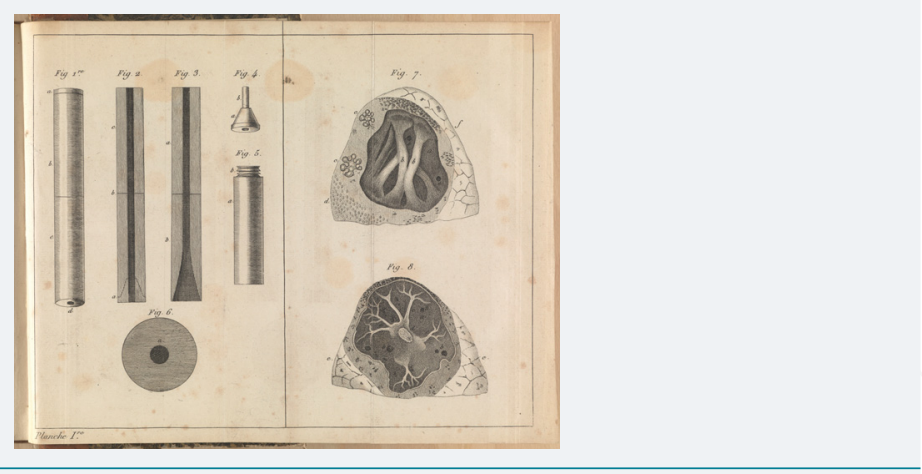

Figure 2: Laënnecs monaural stethoscope from his 1st edition of the book on auscultation [7] from 1819. Two boxwood tubes are screwed together into a $30 \mathrm{~cm}$ long tube. The funnel-shaped hollow end is closed with the obturator to render the heart sounds clearer. To the right is a section of the lung. (Wellcome Library, London). 
some doctors, while others received it with great interest. A valued Glasgow textbook expresses very briefly, "with the stethoscope supposedly some may hear the child's heartbeat", but with a sarcastic addition, "but I do not judge with a normal ear" [8]. As will be seen below, both Forbes and Stokes have had a decisive influence on the prevalence of Laënnec's stethoscopic studies.

John Forbes (1787-1861) worked as a practitioner in Cornwall and later in Chichester. In 1818, he received a primitive monaural model of the Laënnecs stethoscope, which was brought home from Paris by a colleague. This suggested Forbes to translate the two cached works into English. The English version was already available in 1821 [9]. The book received a lot of attention, but also received criticism because of some changes in Laënnec's terminology and description of the lung sounds. The English translation, however, was of great importance, as this made Laënnecs teachings spread to the English-speaking medical world. Its importance also came from the fact that the book was published in several new editions, thus in 1827 , 1829 and 1834.

Irish doctor William Stokes (1804-1878) should also be mentioned in this context. He studied medicine at Edinburgh University, which at this time was commended for his medical education, such as "the Scottish School". Already in the year before the end of Stokes medical education, in 1825 there was a dissertation from his hand entitled "An Introduction to the Use of the Stethoscope" [9]. Here, in connection with the basic works of Laënnec and Forbes, he tries to associate the stethoscopic sounds with the underlying pathology of the chest cavity and the heart. Stokes is also known for his description of the heart block syndrome (Adams-Stokes syndrome) and by the irregular Cheyne-Stokes respiration. Stokes, who worked at Meath Hospital in Dublin, was a unique teacher, clear and educational. He was one of the most cited doctors in the 1900s and was of great importance for the spread of stethoscopy.

\section{Stethoscope's introduction in Denmark}

Oluf Lundt Bang (1788-1877) (Figure 3) was professor at the University of Copenhagen's medical faculty and chief physician at the Royal Frederiks Hospital. He was in Paris in 1823 and was introduced to the new medical auxiliary sciences, chemistry, microscopy and stethoscopy, which he called "the pot, the binoculars and the trumpet" [5]. He had no faith in the first two sciences or could see the benefits of it. However, percussion and stethoscopy he could accept, not least at the meeting with Laënnec and his enthusiasm. This feature is characteristic of the somewhat conservative, but leading professor Bang, whose work took place at the beginning of a breaking time, where the focus on the hospital bed was slowly extended to include

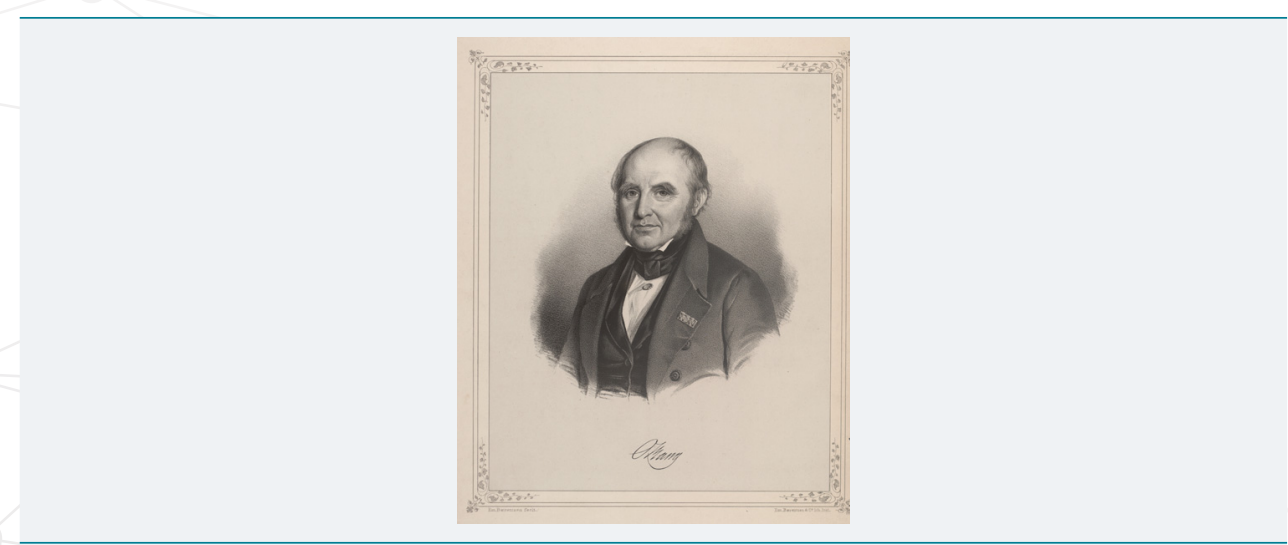

Figure 3: Oluf Lundt Bang (1788-1877), often called Ole Bang, was Professor of Medicine at the University of Copenhagen and chief physician at Frederiks hospital. Bang is nicely portrayed by his grandson, the author Herman Bang as the excellency in the novel "The Gray House" from 1901. Bang went tremendously to the hydrotherapy, where you had to drink a lot of water, and you also had to exercise, ie go long distances and submit different bath procedures (Royal Library, nap_BangOlufLundt03.tif). 
laboratory studies - a development that shared the medical profession and which had not been for easy for Bang [10 pp. 133-40]. After returning to Copenhagen, Bang presented the new method, the stethoscopy, in the Royal Medical Society. Nevertheless he did not become our first stethoscopist - the honor belong to his resident S.M. Trier (1800-1863), who had read the book of Laënnec, where especially the pathologicalanatomical section had fascinated him. Trier acquired a stethoscope and started a self-study at Frederiks Hospital with the many hospitalized patients with pulmonary tuberculosis [5]. In 1830, Trier published the first Danish textbook in stethoscopy, "Anviisning to know Lung and Heart Diseases by Percussion and Medium Auscultation" of 120 pages, which was almost an extract of other textbooks. The Danish textbook was of great importance to the younger doctors. When in 1842 Trier became chief physician at Frederiks Hospital, stethoscopy was now a completely natural part of the clinical medical education and examination of the patients. Although Trier had also referred to Kergaradec's book on the use of the stethoscope in obstetrics, the use of the stethoscope came to its fullest in the 1840s [5]. The development here was carried by H.C. Saxtorph (1813-1875), who in 1840 wrote a licentiate thesis on the use of the stethoscope in the obstetrics and in 1845 defended L.L.Reumert (1812-90) on the subject: The auscultatione obstetricia. Already in 1838, Reumert was rewarded with a medal for the award "About the Progress of Diagnosis, Prognosis and Therapy of Breast Diseases after the Invention of Stethoscopy and Percussion".

With the increasing interest in stethoscopy, one also became aware of how uncertain it was to draw conclusions solely from this study. Emil Hornemann (181070), had received a thorough clinical education in stethoscopy at Frederiks Hospitalet and had also supplemented it with studies in Paris and London. In 1843 he published his textbook "Handbook of Stethoscopy and Stethoscopic Diagnosis". Here he claims that the earlier auscultation, with the ear directly on the chest, could be virtually as good as that obtained with the stethoscope. However, there were certain places on the thorax where the stethoscope was better, as high up in the axillary cavity or by malformed thoracic forms [5].

\section{The binaural stethoscope}

In 1851, the first model of the binaural stethoscope was developed by the Irish physician Arthur Leared (1822-79), and it was presented the same year at the Great Exhibition in London. The following year, a more useful model, with an earplug for each ear, was put into mass production by the doctor George P. Cammann (1804-63) in New York [11]. Cammann worked in New York City as a practitioner at the Northern Dispensary, a relief hospital for the poor. He did not want to patent his stethoscope - it should be available to the doctors. The binaural stethoscope was a great success because it is also used today.

In 1961, the cardiologist, Professor David Littmann (1906- 81) (Figure 4) from Harvard Medical School described the ideal stethoscope" [12]. The project was later realized by the fact that the thoracic part of the stethoscope had two sides, each with

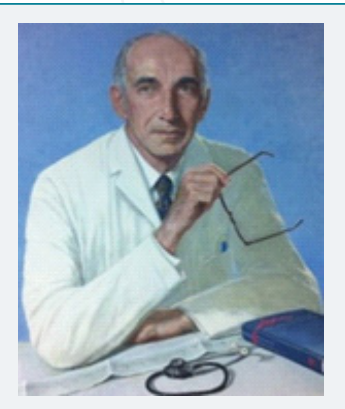

Figure 4: Painting by David Littmann (1906-81) with his stethoscope (3M, USA). 
its own membrane, or alternatively that one membrane was replaced by a cavity, a bell. Hereby one could clearly hear both low frequency and high frequency sounds [13]. To avoid reversing the thoracic part of the stethoscope, a floating membrane was developed which could be adjusted to hear both high and low frequency sounds by manually changing the thoracic portion pressure against the body. Furthermore, the stethoscope was equipped with soft earplugs and with the double lumen ("two tubes in one") to reduce the noise from the surroundings. Littmann patented his stethoscope in 1963 and founded his company Cardiosonics, Inc based in Cambridge Massachusetts. In 1967, the company was acquired by 3M, where Littmann continued as a consultant. $3 \mathrm{M}$ is a US company that develops and sells electromechanical, medical and pharmaceutical products globally to virtually every country in the world. Hereby it became possible to gain widespread knowledge of the new stethoscopes which are intended to cover different clinical purposes. Here the company has contacted leading international cardiologists about the ultimate requirement for the stethoscope. This guide has made $3 \mathrm{M}$ a global leader in stethoscopes.

\section{Blood pressure measurement}

The stethoscope was important for measuring blood pressure. Prior to its introduction, the systolic blood pressure could be measured by the Italian, Scipione Riva-Rocci's method from 1896, where the occlusion cuff was associated with a mercury manometer [14]. Here, palpation had to determine when the pulse ceased at increasing cuff pressure, similar to the systolic BT. A more secure measurement method was obtained by the Russian military doctor Nikolai Sergeevich Korotkoff (18741920). His experimental work took place at the military academy in St. Petersburg, but also under the precarious and harsh conditions of the Russian-Japanese war 1904-5, as well as during the medical work in the Siberia mining district and the work with the invalids [15]. Korotkoff replaced the palpation by the Riva-Rocci's method with the stethoscope, where he listened to the "Korotkoff sounds" produced under the cuff. With decreasing cuff pressure, the appearance and disappearance of the pulse sound was revealed as the systolic and diastolic blood pressure, respectively. This was the breakthrough in modern blood pressure measurement.

\section{Stethoscope today}

Binaural stethoscopes are today available in many colors, types, qualities and with an ergonomic design and they are more hypoallergenic, so do not contain latex or phthalates. The stethoscope also has other uses, such as by listening to the stomach and vessel, where the sound can help reveal inter alia intestinal loop and arteriosclerotic vascular constriction.

There are special stethoscopes for studying children and newborns. When examining the fetus, the midwife still often uses the monaural stethoscope (listener), where one can best hear the heart sounds. The stethoscope is called Pinard's stethoscope, which refers to Adolphe Pinard (1844-1934), who was a French obstetrician and pioneer in the perinatal care of the pregnant woman [16]. But the value of the classic stethoscope is currently limited. Therefore, it became a major advance as the condition of the fetus and the newborn could be monitored electronically, as with ultrasound, if a congenital heart failure was suspected [17].

Electronic stethoscopes have been developed and they have become very popular $[13,18]$. They utilize the latest technologies for digital signal processing with wireless digital transfer between stethoscope and computer, thereby leading the stethoscopes from the mechanical and analog world into the digital world with its great potential (Figure 5). There are many possibilities in documentation and data processing, since heart and lung sounds can now be stored electronically, compared and forwarded to experts or colleagues or used as documentation in any complaints. Here, weak heart 
and lung sounds can be amplified, and external noise can be dampened. The sounds can be reproduced at a lower speed and at the same pitch so that even small details in the sound image can be examined more precisely. The sound waves are picked up by a microphone and converted, via a piezoelectric sensor, into electrical signals that can transmit and play the heart and lung sounds on a PC via wireless bluetooth technology or present them graphically. The fascinating technical development of the electronic stethoscope mentioned here is due to Medicom Innovation Partner (formerly Bang \& Olufsen Medicom) [19]. After contact with 3M Health Care (3M Littmann), the stethoscope was marketed as Littmann electronic stethoscope, which today is the globally leading stethoscope.

The technological development of imaging diagnostics has opened up increasingly refined scientific observations with objective facts as a basis for medical diagnosis.

The stethoscope can now also be worn visibly, where it shows that you are a doctor (Figure 6). Today, heart and lung studies also include X-ray scans, ECG and ultrasound scanning. The latter is based on an ultrasound source (probe) which is carried down over the body. Reflected ultrasound waves will form an image of e.g. the heart. Combining this echocardiographic image with dopler technique measuring the velocity and direction of blood flow in the heart, leaks can be revealed in heart valves and septum, where a blood syringe through the septum can be revealed by a blue-green color in the two-dimensional echocardiography image with color -doppler technique $[17,20]$. The two-dimensional (2D) echocardiography image was developed around 1970, and a three-dimensional (3D) representation of the heart's structures is on its way - perhaps it may fulfill the desire for better anatomy visualization in connection with, for example, mitral and septal defects [21,22]. With transoesophageal echocardiography, a very clear picture of the heart and heart valves at the short distance to the heart is achieved when the ultrasound head is placed in the esophagus. This has been implicated in the diagnosis of endocarditis, intracardiac thrombosis and aortic lesions [21].

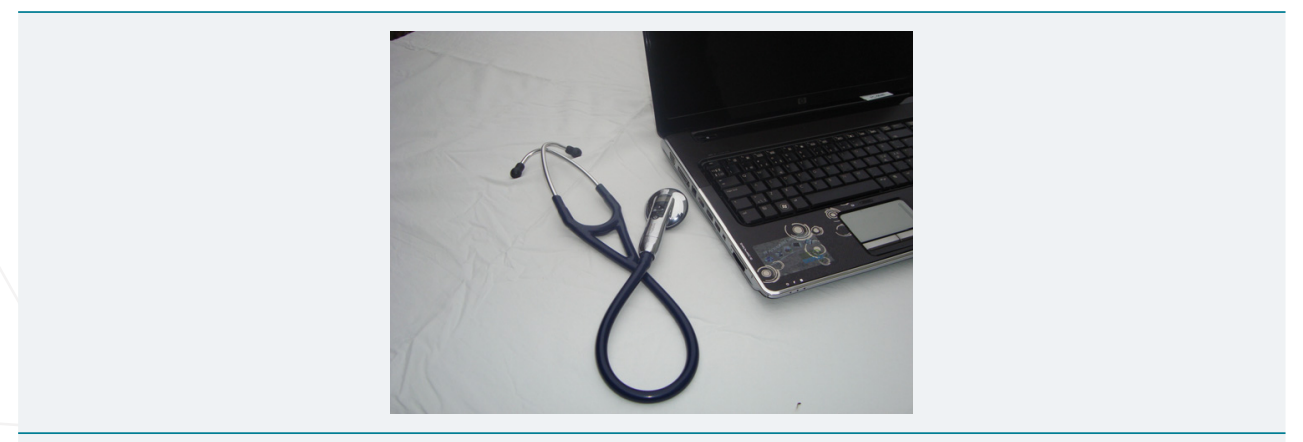

Figure 5: A newer 3M Littmann electronic stethoscope Model E-3200 with bluetooth technology that enables wireless transfer to computer for graphic or audio reproduction, analysis, deposition and forwarding.

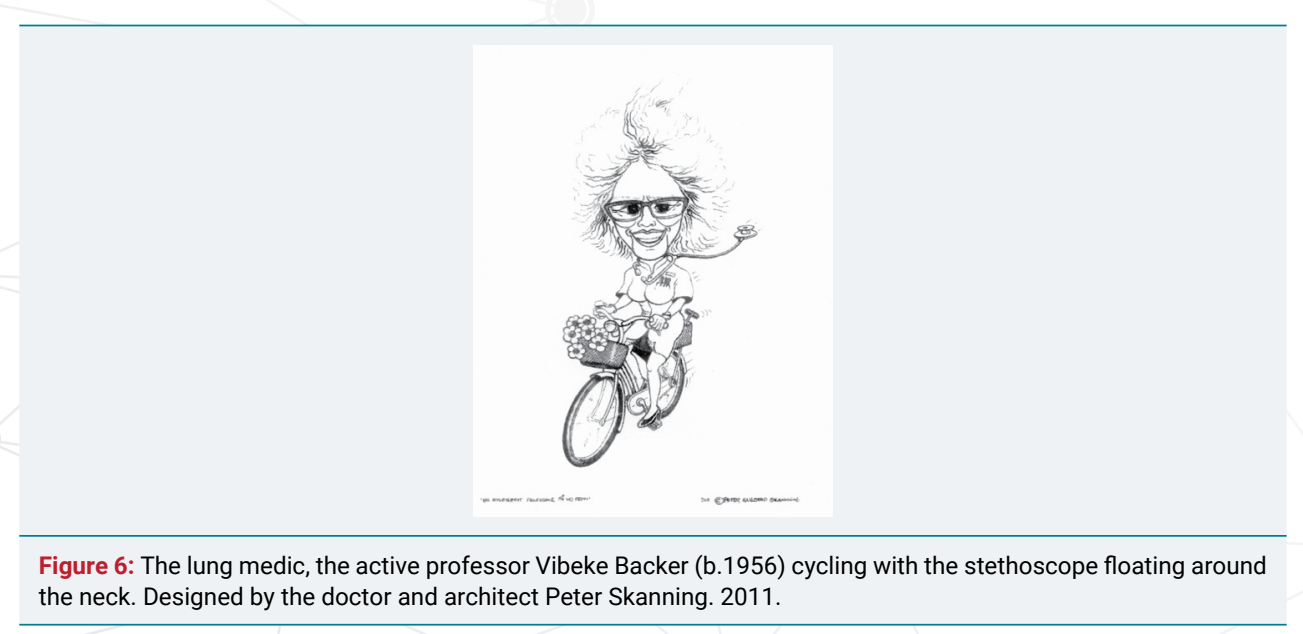


In addition to these advanced special studies, it is hoped that in the future the stethoscope may be expanded to accommodate also an easily portable and handy ultrasound scanning apparatus for examining not only heart and lungs, but also many other organs as part of the mobile computer can see the images of that body. This allows the examination to take place both during the study, in the outpatient clinic or at the patient's home. The goal here is to obtain a sufficiently good diagnosis, which in many cases will be able to replace the need for more advanced studies.

Thus, the Laënnecs primitive stethoscope, which was the start of a diagnosis of cardiovascular and pulmonary disorders, has over 200 years developed into a meticulous study of malfunctioning of the organs - a medical success which is not least due to a rapid development in the field of medical technology interaction between doctors and engineers. The stethoscope thus has a future based on new advanced technology that expands and improves the diagnostic capabilities.

\section{Resume}

\section{The stethoscope - for 200 Year}

René T.H. Laënnec was the man who designed the first monaural instrument for mediate auscultation. The invention became a medical breakthrough. An instrument capable of enhancing the subtle sounds created by the human heart and lungs. This revolutionary instrument also had the benefit of decreasing the oftentimes too direct bodily contact between the doctor and the patient. Laënnec carefully described the different sounds created by the human organs and attempted to link them to the post mortem findings. Even though many doctors were enthusiastic regarding this new medical breakthrough, the stethoscope also had its opponents, but John Forbes' English translation of Laënnec's "De l'auscultation médiate" as well as William Stokes' treatise on the use of the stethoscope spread the news to the medical world. In Denmark the stethoscope was introduced by Oluf Lundt Bang, S.M. Trier and E. Hornemann. The next step forward was the development of the binaural stethoscope by G.P. Camman in New York. The Littmann Electronic Stethoscope (3M Health Care) created by David Littmann is considered the leading product globally in this medical field. Digitization, ultrasound and Doppler Effect, as well as 2D and 3D printing, are evidence of an ongoing evolution within this field of medical equipment for more than 200 years.

\section{References}

1. Loeb Classical Library: Hippocrates. Diseases II. 1988; 5: 61: 306-307. Ref.: https://goo.gl/dHinsJ

2. Hajar R. The art of listening. Heart Views. 2012; 13: 24-25. Ref.: https://goo.gl/h6uVrp

3. Gotfredsen E. The History of Medicine. Copenhagen: New Nordic Publisher Arnold Busck. 1964.

4. Walker HK, Hall WD, Hurst JW, ed. Clinical Methods: The history, physical and laboratory examinations. 3rd edition. Boston: Butterworths, 1990; Chapter 1. Ref.: https://goo.gl/8BiYMh

5. Bastholm E. Laennec and the stethoscope. Danish Medical History Yearbook. 1982; 112-35

6. Roguin A. Rene Theophile Hyacinthe Laënnec (1781-1826): The man behind the stethoscope. Clin Med \& Res. 2006; 4: 230-235. Ref.: https://goo.gl/oBVb9b

7. Laënnec RTH. The consultation will provide you with the diagnostic of the maladies of the poems and the body. 1st ed. Paris: Brosson et Chaude. 1819.

8. Pinkerton JH. John Creery Ferguson (1802-1865) Physician and Fetologist. Ulster Med J. 1981; 50: 10-20. Ref.: https://goo.gl/ym6oeR

9. Agnew R. The prelude to stethoscopy: some French, British and Irish contributions in the early nineteenth century. J Med Biogr. 2003; 11: 135-141. Ref.: https://goo.gl/BL5v4Z

10. Skydsgaard MA. Ole Bang and a wrestling time in Danish medicine. Aarhus: Aarhus Universitets for lag. 2006

11. Peck P. Dr. Camman and the binaural stethoscope. J Kansas Med Soc. 1963; 64: 121-123. Ref.: https://goo.gl/AivsP9 
12. Littmann D. An approach to the ideal stethoscope. JAMA. 1961; 178: 504-505. Ref.: https://goo.gl/dXpTqe

13. Ref.: https://goo.gl/k9UKiW

14. Estanol B, Delgado G, Borgstein J. Korotkoff sounds - the improbable also occurs. Arq Bras Cardiol. 2013; 101: e99-e100. Ref.: https://goo.gl/YBtEWX

15. Laher M, O'Brien E. In search of Korotkoff. Brit Med J. 1982; 285: 1796-1798. Ref.: https://goo.gl/osDJLq

16. Dunn PM. Adolphe Pinard (1844-1934) or Paris and intrauterine pediatric care. Arch Dis Child Fetal Neonatal Ed. 2006; 91: F231-F232. Ref.: https://goo.gl/29N3z9

17. Ref.: https://goo.gl/YY8q17

18. Leng S, Tan RS, Chai KTC, Wang C, Ghista D, et al. The electronic stethoscope. BioMed Eng Online. 2015; 14: 66. Ref.: https://goo.gl/fJWeNn

19. Ref.: https://goo.gl/T1mT3H

20. Ref.: https://goo.gl/F8cKjB

21. Ihlen $\mathrm{H}$. The development of echocardiography - from "coffee grounds" to 3D real time. Heart Forum 2009; 22: 6-9.

22. Autumn N. Dansk Cardiologisk Selskab's 50th anniversary. Echocardiography Working Group. Cardiological Forum. 2010; 51-52. 